\title{
Agenda for Future Research in Melasma: QUO VADIS?
}

\section{Saumya Panda*}

Professor, Department of Dermatology, KPC Medical College, Kolkata, India

Our understanding of melasma as a disease has undergone a radical shift in the past decade or two [1]. The landmark paper by Sanchez et al. published in 1981 first provided for a structured model of the disease based on clinical, light microscopic, ultrastructural, and immunofluorescence findings [2]. The rigid structural model proposed at that time dividing melasma into epidermal, dermal and mixed subtypes has, of late, been questioned by studies employing modern investigational techniques, viz., in vivo Reflectance Confocal Microscopy (RCM), Immunohistochemistry (IHC), and electron microscopy. Thus, currently melasma is viewed as being much more than just about the abnormal deposition of melanin and altered disposition of melanocytes. Evidence of dynamic interaction of melanocytes with a number of cellular elements, including keratinocytes, dermal fibroblasts and vascular endothelium, and induction of epithelial-mesenchymal transition [3] have been recently found in melasma, turning its pathophysiology into a highly dynamic and complex process.

It will be facile to interpret such probing investigations, seeking to unearth the natural dynamics of melasma, as being driven purely by technological advances in the investigative techniques. Though such advances obviously had a crucial role to play in these studies, a major driving force has been the lack of a satisfactory treatment in most of the cases of melasma.

Hydroquinone (HQ, alone, or as a major component of the triple combination formulation, devised by Kligman and Willis in 1975, [4] along with tretinoin and topical steroid) has been, for long, considered 'the gold standard' of hypopigmenting therapy by researchers and clinical dermatologists alike [5]. The main mechanism of HQ being reversible inhibition of melanin synthesis by competitive blocking of tyrosinase, it could account for the fact that epidermal melasma of the classical model characterized by hyperactive melanocytes synthesizing copious amounts of melanin is more sensitive to treatment than dermal melasma characterized by dermal melanophages that are essentially melanin stores. Because of the relative lack of effectiveness of HQ (and triple combination) in removing stored melanin of dermal melasma, the need for long wavelength lasers was felt that would selectively target dermal melanin. But two decades of use of lasers and light-based treatments in melasma have been unable to produce sufficient evidence that any of those work except, possibly, in very short-term [6].

Thus, melasma research today is at an intriguing crossroads. On one hand, the rigid structural classical model of the disease is facing a veritable question mark. On the other hand, the contours of the novel dynamic model based on epidermal-dermal (epithelial-mesenchymal) interactions are yet to be clearly delineated, lending a further degree of uncertainty to our understanding of melasma.

Ironically, the current understanding of melasma pathophysiology, that owes a great deal to technological advances like RCM in the first place, is also circumscribed by the limitations of the same investigative techniques. For example, based mainly on the RCM findings the current paradigm gives, at best, only a peripheral importance to dermal melanophages, and promotes the concept that the true primary histologic target is epidermal melanin in the lesional skin [5]. However, we should be careful as we try to integrate this concept based on RCM findings into emerging management models and novel therapeutic targets, once we realize that a major technical limitation of RCM is the narrow thickness of the field of imaging [7]. This inherent technical lacuna might have biased many of the RCM studies toward stressing melasma more as an epidermal disease than a dermal one [1].

Let us take another example from the domain of therapeutics, when a new line of treatment was advocated based on a novel finding in melasma pathophysiology. This is regarding the putative role of vascular endothelium in the development of melasma that was put forward following a series of studies identifying increased expression of Vascular Endothelial Growth Factor (VEGF) as a major angiogenic factor for altered vessels in melisma [8]. Emergence of this concept has led to the use of Tranexamic Acid (TXA), which is a plasmin inhibitor and a lysine analogue. Plasmin converts extracellular matrixbound VEGF into freely diffusible forms [9]. Thus TXA suppresses angiogenesis. However, the promise of TXA used in whatever form (oral, topical etc) is yet to be translated into clinical evidence. The data from small, uncontrolled, open trials point to a very modest, very short-term improvement and nothing more [10].

Similarly, the use of Pulsed Dye Laser (PDL) in melasma was purely based on the theory that vascularization plays an important role in its pathogenesis. Melanocytes express VEGF receptors -1 and -2 [11]. PDL, and to an extent, quality-switched neodymium-doped yttriumaluminium garnet laser (QS-Nd:YAG) laser, [12] purportedly decrease melanocyte stimulation by antiangiogenic mechanism. However, the use of lasers, of whichever variety, is fraught with the challenge of Postinflammatory Hyperpigmentation (PIH) that is particularly persistent and resistant in the darker population. 1 The authors of the Randomized Controlled Trial (RCT) on PDL concluded that this was due to the laser targeting melanin [13]. Moreover, other than several methodological flaws that seem to be common to all the studies with lasers in melasma (e.g., small sample size, lack of blinding, asymmetrical sampling in the split-face studies), the positive clinical responses could be ascertained over only a short or very short term, leading to the conclusion that these are, at best, of uncertain clinical effectiveness [6].

The lack of evidence of the effectiveness of treatments targeting the vascular elements in melasma renders the following query all the more pertinent: Is the dermal activity involving the fibroblasts and the vascular elements a primary event or an epiphenomenon?

This question has been severally asked and answers have been sought through different strategies, though it has to be said that till now none of those strategies seem to have been particularly successful. Rather, these have led us to more questions. One study carried out in Korea attempted to look beyond the paracrine and autocrine activation

*Corresponding author: Saumya Panda, Professor, Department of Dermatology, KPC Medical College, Kolkata, India, Tel: +91-9831163975; E-mail: saumyapan@gmail.com

Received October 8, 2014; Accepted October 14, 2014; Published October 16, 2014

Citation: Panda S (2014) Agenda for Future Research in Melasma: QUO VADIS? Pigmentary Disorders 1:e103. doi:10.4172/JPD.1000e103

Copyright: @ 2014 Panda S, et al. the terms of the Creative Commons Attribution License, which permits unrestricted use, distribution, and reproduction in any medium, provided the original author and source are credited. 
of lesional melanocytes in the pathogenesis of melasma, and identified a distinctly inflammatory subgroup of the disease characterized by significantly more CD68+ melanophages, CD117+ mast cells, and leucocyte common antigen (LCA)+ leucocytes in the lesional dermis [14]. The authors hypothesized that melasma, or at least a subtype of it, could be a solar PIH caused by subclinical inflammation induced by ultraviolet (UV) light. However, the histopathologic characteristics of chronic solar damage, viz., rete ridge flattening, solar elastosis etc, might be epiphenomena of UV radiation [15].

Melasma is indeed complex, and the maze-like pattern of its pathogenesis is difficult to decipher. Thus, we come across such speculations as that melasma is nature's way to compensate for the high ambient UV flux in tropical countries and any method to remove it would probably lead to indifferent results and rapid recurrence [16]. Of course, such armchair theorizing would spawn nothing except therapeutic nihilism.

But, beyond all those guesses and surmises, there is serious research going on to solve basic, yet as of now unanswered, problems. One such concerns the distribution of facial melasma. One of the fundamental contributions of the classical Puerto Rican study by Sanchez et al. [2] was the morphological classification of melasma into three subtypes: centrofacial, malar, and mandibular. Of these, the existence of the mandibular type was questioned in a subsequent study carried out, again, in Puerto Rican women by one of the workers involved in the earlier study [17]. But other than the uncertainty over the mandibular type, the overall pattern and distribution of facial melasma, adequately incorporated by the centrofacial and malar types, are generally accepted. Combination patterns of melasma in the same patient (e.g., centrofacial plus malar, etc), as described in an Indian study [18], should be similarly viewed with circumspection as, like mandibular melasma, histopathology might demonstrate that these previously unreported patterns represent some clinical entity entirely different from melasma.

All said and done, the accepted morphological patterns of melasma demonstrate that the most irradiated areas of the face (e.g., nose, glabella) do not coincide with the highest frequency of melasma sites, leading to the assumption that factors other than UV radiationmust be involved in the disease development. Indeed, large epidemiological case-cxontrol studies have confirmed that that other than chronic sun exposure, darker skin phototypes having greater pigmentation capacity, family ancestry, sexual hormonal stimuli and psychological stress are independent risk factors associated with melisma [19].

Such epidemiological data is supported by immunohistochemical analysis, viz., high epithelial expression of melanocortin-1 receptor (MC1-R), alpha-melanocyte stimulating hormone ( $\alpha-\mathrm{MSH})$, estrogen receptor (ER)- $\beta$, progesterone receptor etc, that suggest that the whole epidermal melanin unit (EMU) is involved in melasma pathophysiology [20]. Profilometry and grayscale fractal dimension analysis has proven that basal keratinocytes from facial melasma display changes in nuclear form and chromatin texture, further illustrating that the phenotypic differences between melasma and adjacent facial skin can result from complete EMU alterations, and not just due to hypertrophic melanocytes [21]. Specific genomic alterations and epigenetic factors (e.g., sexual hormones and UV radiation) can locally modify the secretion pattern of the several inflammatory, growth and melanogenic factors produced by keratinocytesn [22]. Though many of these cytokines have been unraveled, we cannot answer why only certain areas of the face are selectively more involved than others, nor we completely know the interlinkages between the hormonal and the
UV-induced cytokines. However, already a topical agent (undecylenoyl phenylalanine $2 \%$ ) has been tested in a double-blind vehicle-controlled study that demonstrates skin-lightening effect only by virtue of being an $\alpha$-MSH and $\beta$-adrenergic receptor anatagonist [23].

With so much of uncertainty pervading the disease pathophysiology, it is only expected that there would be lots of unanswered queries regarding even the basic management principles of melasma. For instance, there is no study of effectiveness of preventive measures (e.g., preventing exposure to sources of UV light like sunlight) or therapeutic interventions in high-risk populations of melasma (e.g., women having undergone recent delivery, on oral contraceptive pills or on hormone replacement therapy). This is because all studies exclude patients with known risk factors of the disease. Thus, strange as it may seem, there is no good evidence to support any preventive intervention in high-risk populations in melasma. Neither is there any good evidence to support any therapeutic intervention in childbearing, pregnant or breastfeeding women, including the use of broad-spectrum sunscreens [6]. As all effectiveness trials of therapeutic interventions have been performed in non-childbearing women, we should be very careful in extrapolating the results in clinical practice to those requiring the interventions the most that is the high-risk populations who are routinely excluded from these trials. This is a quizzical situation indeed! Similar is the situation with therapeutic interventions for melasma in men, with no trials having been carried out exclusively in that population. The RCTs that included males as subjects did not carry out a subgroup analysis for them. In fact, none of them would have had sufficient power to identify clinically relevant differences at all [6].

Similar therapeutic uncertainty permeates the effectiveness of sunscreens in melasma. The limited evidence from a single RCT found no additional benefit in patients using sunscreens as a therapeutic agent [24]. There is a need to revalidate the findings of this RCT due to several reasons. Recently, it has been shown that although both long wavelength UVA (UVA1) and visible light can induce pigmentation in skin types IV to VI, pigmentation induced by the latter is darker and more sustained [25]. This gives a clue why treating melasma in darker skin poses a more formidable challenge. It also underscores the need for development of filters that protect against visible light. Such ultra-spectral filters (encompassing UVA1, 340 - $400 \mathrm{~nm}$, and visible light, $400-700 \mathrm{~nm}$ ) are currently not available [1]. Recently, it has been brought to light that heat (Infrared Radiation, IR) also generates similar molecular and ultrastructural changes as UV radiation in melisma [26]. So this makes the examination of clinical effectiveness in melasma of even the broadest spectrum sunscreen available today all the more relevant.

Interpreting therapeutic effectiveness has proved to be particularly challenging in melasma. This has got as much to do with the natural dynamics of the condition as with the nature of the therapeutic interventions. Considering the tendency of incessant relapse of the condition irrespective of the therapeutic modality, a systematic review has recommended that all clinical trials in melasma should have an intervention period of at least six months and there should be longterm follow-up for at least 12 months following the intervention to assess the maintenance of response [27]. That is not an easy ask, and it is not surprising that no RCT having such a long duration of treatment or post-treatment follow-up is available.

The road from in vitro research to double-blind RCTs seems particularly long and tortuous in melasma, with many of the promising molecules falling by the wayside in between. For example, in vitro studies with azelaic acid have shown a significant interference with 
DNA synthesis and mitochondrial enzymes in abnormal, hyperactive melanocytes, while leaving normally functioning melanocytes unharmed [28]. So it would seem that azelaic acid would be the perfect hypopigmenting agent for melasma, in which hyperactive melanocytes accounted for much of the disease activity. However, when azelaic acid was compared with HQ $2 \%$ and $4 \%$ respectively, in two different RCTs, no statistical difference in the two groups could be found with the objective measures of reduction, either in lesion size or pigmentary intensity [29,30]. This could reflect either the fact that other than hyperactive melanocytes, there are many other mechanisms behind the development of melasma, or simply that the in vitro effects of azelaic acid are not clinically reproducible.

Such lack of clinical reproducibility of test tube experiments is most acutely observed among the botanicals and cosmeceuticals. A number of botanicals, notably licorice extract [31], soy extract [32], Glechoma hedercea extract [33], silymarin cream derived from milk thistle (Silybum marianum) [34] among topicals and procyanidin [35], pycnogenol (standardized extract of French maritime pine bark) [36], Polypodium leucotomos extract [37], and Chinese herbs [38] among oral agents flattered to deceive in subsequent wellcontrolled clinical trials $[39,40]$. The major limitations of most of these studies are inconsistencies in study methodology and botanical extraction method. Controlling for confounding variables, such as sun exposure and sunscreen use, is difficult in clinical studies on melasma. Also, the potency, pharmacodynamics, and composition of active phytochemicals vary significantly with different extraction methods [41]. For example, Cuscuta chinensis seeds have been traditionally used to treat melasma in Chinese medicine. However, in accordance with traditional usage, when both the water fraction and the ethanol fraction of Semen cuscutae were extracted, mushroom tyrosinase assay showed that the water fraction was an uncompetitive inhibitor of mushroom tyrosinase, whereas the ethanol fraction resulted in dose-dependent activation of mushroom tyrosinase [42].

Many other treatment modalities in melasma suffer from such difficulties of standardization and comparability. A common example is glycolic acid (GA). The sheer variety of concentrations apart, the efficacy and tolerability of individual GA peel formulations are dependent on a multitude of factors, viz., buffering, bioavailability, $\mathrm{pH}$, neutralization, proportion of free acid etc. [43]. As a result, the evidence to assess the effects of GA peels in melasma is deemed to be insufficient.
Similar is the situation with cosmeceuticals. From time to time, a number of such formulations, namely Gigawhite [44], rucinol (4-n-butylresorcinol) [45], Thiospot [46], Lumixyl (a synthetic oligopeptide that is a competitive inhibitor of tyrosinase) [47] etc, have been trialled in RCTs, but due to severe methodological limitations none of these could provide a good, reliable evidence of certain effectiveness in the treatment of melasma. As direct fallout of such uncertain effectiveness of any new cosmeceutical depigmenting agent, cosmetic skin lightening - that is a globally prevalent practice - has become a health hazard due to hidden heavy metal toxicity. In a spectrometric analysis of the content of mercury, a melanotoxin whose property is known since ages, in 549 skin lightening products procured globally, as much as $6 \%(\mathrm{n}=33)$ was found to contain mercury above 1000 parts per million.

As mentioned before, there have been numerous studies of lasers and light therapies in melasma, but till now none of them could provide conclusive evidence of significant effectiveness. Among the promising novel light-based therapies, a pulse-in-pulse mode (multiple fractionated subpulses in one pulse width) intense pulsed light has been developed in South Korea [48,49]. Among novel lasers, a copper bromide (CuBr) laser, which emits dual wavelengths ( 511 and $578 \mathrm{~nm}$ ), thus enabling simultaneous and selective destruction of melanin and hemoglobin, was found to be ineffective in improving melasma in a study conducted in Thailand among patients with skin phototypes III to $\mathrm{V}$ [50]. This serves to post a bigger question mark on the vascular theory of pathogenesis of melasma. Another Thai study tested a $1410 \mathrm{~nm}$ fractional photothermolysis laser in a patient population presumably having a similar phototype. Like all lasers showing effectiveness in melasma, the results were temporary. More interestingly, it was concluded that only 5 per cent coverage should be used to minimize risk of adverse effects, raising questions about the safety of the procedure, particularly in the heavily pigmented population [51]. Lowfluence Q-switched Nd: YAG laser, that seems to have acquired the status of 'gold standard' among lasers in melasma by virtue of a lower incidence of inducing PIH (though its effectiveness is as short-term as all other lasers), is the one against which all the new lasers are tested for comparative efficacy and safety. Low-fluence Q-switched alexandrite laser $(755 \mathrm{~nm})$ was found to be of equal effectiveness [52]. and lowpower fractional carbon dioxide $\left(\mathrm{CO}_{2}\right)$ laser significantly more effective than low-fluence Q-switched Nd: YAG laser (1, $064 \mathrm{~nm})$ [53]. All of these studies share the limitations of previously done studies with lasers

\begin{tabular}{|c|c|c|}
\hline $\begin{array}{l}\text { Grey areas and research interests in } \\
\text { pathophysiology }\end{array}$ & $\begin{array}{l}1 . \\
2 . \\
3 . \\
4 . \\
5 . \\
6 .\end{array}$ & $\begin{array}{l}\text { Is the dermal activity involving fibroblasts and vascular tissues a primary event or an epiphenomenon? } \\
\text { Epigenetic linkages between the hormonal receptors and the UV-induced cytokines } \\
\text { Why are only certain areas of face preferentially involved, and simply not those areas which get the most solar } \\
\text { radiation? } \\
\text { Role of infrared radiation (heat) in melasma } \\
\text { Integrative research for assimilation of light microscopic, RCM, IHC and electron microscopic findings } \\
\text { Technical improvisation in RCM: panlesional microscopy with enhanced depth }\end{array}$ \\
\hline Clinical questions & $\begin{array}{l}1 . \\
2 . \\
3 .\end{array}$ & $\begin{array}{l}\text { Is melasma one disease or several? } \\
\text { Is there really an entity called mandibular melasma? } \\
\text { A proper delineation of melasma in males - should } \mathrm{h} / \mathrm{p} \text { be mandatory for diagnosing melasma in males? }\end{array}$ \\
\hline $\begin{array}{l}\text { Therapeutic research and research } \\
\text { methodology in melasma }\end{array}$ & $\begin{array}{l}1 . \\
2 . \\
3 . \\
4 . \\
5 . \\
6 . \\
7 .\end{array}$ & $\begin{array}{l}\text { Subgroup analysis by subdividing patient population according to depth of melasma, or objective measurements, viz., } \\
\text { colorimetry, corneomelametry, which would lead to more reproducible outcome measures? Or both would, equally? } \\
\text { Methodological harmonization: studies with proper sample size, proper blinding, symmetrical sampling, at least } 24 \\
\text { weeks' intervention period, post-intervention follow-up for at least } 12 \text { months } \\
\text { Studies investigating preventive intervention } \\
\text { Therapeutic intervention in high-risk populations } \\
\text { Therapeutic intervention in male melasma } \\
\text { How effective are sunscreens, per se, in preventing melasma? } \\
\text { How to ensure better reproducibility of trials with therapeutic agents and procedures that are difficult to standardize, } \\
\text { namely, botanicals, acid peels and cosmeceuticals? }\end{array}$ \\
\hline
\end{tabular}

Table 1: Unresolved issues and a wish list for future research in melasma. 
in melasma, viz., very short-term results, failure to prevent recurrence after completion of treatment, high rate of PIH, etc.

To conclude: Our knowledge of melasma has grown in exponential fashion, but almost in equal proportion to the gaps in between. So, the more we seem to know of the condition, the more, it appears that, we do not know of it. The basic knowledge gaps and the research agenda on our plate, with reference to pathophysiology, clinical aspects and management of the disease, have been summarized in Table 1. A glance at it would make it obvious that many of these unsolved problems are interrelated. For example, the role of heat on melasma, if adequately answered, could justify the preventive role, or lack of it, of the widest spectrum sunscreen available today. Or, the mystery of distribution pattern of facial melasma can only be resolved once the epigenetic linkages between hormonal receptors in the skin and UVrelated cytokines are further explored. More frequent employment of techniques of objective measures of pigmentation, viz., colorimetry ( $\mathrm{L}^{*} \mathrm{a}^{*} \mathrm{~b}^{*}$ system) [54] and corneomelametry [55] will certainly lead to standardization of measures of outcome of future studies. Improved standards of methodology in RCTs on melasma, and better reproducibility of future trials, particularly with regard to peeling agents, botanicals and cosmeceuticals, can certainly usher in hope for a new wave of effective therapeutic agents.

\section{References}

1. Panda S (2014) Recent trends and future treatment paradigms of melasma based on current understanding of pathophysiology, in Lahiri K, Chatterjee M, Sarkar R (eds). Pigmentary disorders: a comprehensive compendium (1st edn), Jaypee Brothers, New Delhi, pp. 349-360.

2. Sanchez NP, Pathak MA, Sato S, Fitzpatrick TB, Sanchez JL, et al. (1981) Melasma: a clinical, light microscopic, ultrastructural, and immunofluorescence study. J Am Acad Dermatol 4: 698-710.

3. Kim NH, Choi SH, Lee TR, Lee CH, Lee AY (2014) Cadherin 11, a miR-675 Target, Induces N-Cadherin Expression and Epithelial-Mesenchymal Transition in Melasma. J Invest Dermatol.

4. Kligman AM, Willis I (1975) A new formula for depigmenting human skin. Arch Dermatol 111: 40-48.

5. Aurangabadkar S, Panda S (2014). Pigment polemy: the use of lasers for melasma. Pigment Bulletin 2: 18-23.

6. Salim A, Rajaratnam R, Domanne ES (2014). Melasma, in Williams HC (ed) Evidence-based dermatology (3rd edn), Wiley Blackwell/BMJ Books, Oxford, pp. $470-485$

7. Debarbieux S, Depaepe L, Poulalhon N, Dalle S, Balme B, et al (2013). Reflectance confocal microscopy characteristics of eight cases of pustular eruptions and histopathological correlations. Skin Res Technol 19: e444-e452.

8. Kim EJ, Park HY, Yaar M, Gilchrest BA (2005) Modulation of vascular endothelial growth factor receptors in melanocytes. Exp Dermatol 14: 625-633.

9. Ferrara N (2010) Binding to the extracellular matrix and proteolytic processing two key mechanisms regulating vascular endothelial growth factor action. Mol Biol Cell 21: 687-690.

10. Li Y, Sun Q, He Z, Fu L, He C, et al. (2014) Treatment of melasma with oral administration of compound tranexamic acid: a preliminary clinical trial. J Eur Acad Dermatol Venereol 28: 393-394.

11. Plonka PM, Passeron T, Brenner M, Tobin DJ, Shibahara S, et al. (2009) What are melanocytes really doing all day long...? Exp Dermatol 18: 799-819.

12. Arora $P$, Sarkar R, Garg VK, Arya L (2012) Lasers for treatment of melasma and post-inflammatory hyperpigmentation. J Cutan Aesthet Surg 5: 93-103.

13. Passeron T, Fontas E, Kang HY, Bahadoran P, Lacour JP, et al. (2011) Melasma treatment with pulsed-dye laser and triple combination cream: a prospective, randomized, single-blind, split-face study. Arch Dermatol 147: 1106-1108.

14. Noh TK, Choi SJ, Chung BY, Kang JS, Lee JH, et al. (2014) Inflammatory features of melasma lesions in Asian skin. J Dermatol 41: 788-794.
15. Kang WH, Yoon KH, Lee ES, Kim J, Lee KB, et al. (2002) Melasma: histopathological characteristics in 56 Korean patients. Br J Dermatol 146: 228237.

16. Sardana K, Garg VK (2014). Lasers are not effective for melasma in darkly pigmented skin. J Cut Aesth Surg 7: 57-60.

17. Mandry Pagán R, Sánchez JL (2000) Mandibular melasma. P R Health Sci J 19: $231-234$

18. Krupa Shankar DS, Somani VK, Kohli M, Sharad J, Ganjoo A, et al. (2014) A cross-sectional, multicentric clinico-epidemiological study of melasma in India. Dermatol Ther (Heidelb) 4: 71-81.

19. Handel AC, Lima PB, Tonolli VM, Miot LD, Miot HA (2014) Risk factors for facial melasma in women: a case-control study. Br J Dermatol 171: 588-594.

20. Jang YH, Lee JY, Kang HY, Lee ES, Kim YC (2010) Oestrogen and progesterone receptor expression in melasma: an immunohistochemical analysis. J Eur Acad Dermatol Venereol 24: 1312-1316.

21. Brianezi G, Handel AC, Schmitt JV, Miot LDB, Miot HA (2014). Changes in nuclear morphology and chromatin texture of basal keratinocytes in melasma. $\mathrm{J}$ Eur Acad Dermatol Venereol.

22. Cardinali G, Kovacs D, Picardo M (2012) Mechanisms underlying postinflammatory hyperpigmentation: lessons from solar lentigo. Ann Dermato Venereol 139 Suppl 4: S148-152.

23. Katoulis A, Alevizou A, Soura E, Mantas N, Bozi E, et al (2014). A double-blind vehicle-controlled study of a preparation containing undecylenoyl phenylalanine $2 \%$ in the treatment of melasma in females. J Cosmet Dermatol 13: 86-90.

24. Vázquez M, Sánchez JL (1983) The efficacy of a broad-spectrum sunscreen in the treatment of melasma. Cutis 32: 92, 95-96.

25. Mahmoud BH, Ruvolo E, Hexsel CL, Liu Y, Owen MR, et al. (2010) Impact of long-wavelength UVA and visible light on melanocompetent skin. J Invest Dermatol 130: 2092-2097.

26. Cho S, Shin MH, Kim YK, Seo JE, Lee YM, et al. (2009) Effects of infrared radiation and heat on human skin aging in vivo. J Investig Dermatol Symp Proc 14: 15-19.

27. Rajaratnam R, Halpern J, Salim A, Emmett C (2010) Interventions for melasma Cochrane Database Syst Rev : CD003583.

28. Yu JS, Kim AK (2010) Effect of combination of taurine and azelaic acid on antimelanogenesis in murine melanoma cells. J Biomed Sci 17 Suppl 1: S45.

29. Baliña LM, Graupe K (1991) The treatment of melasma. $20 \%$ azelaic acid versus 4\% hydroquinone cream. Int J Dermatol 30: 893-895.

30. Sivayathorn A, Verallo RV, Graupe K (1995). $20 \%$ azelaic acid cream in the topical treatment of melasma: a double-blind comparison with $2 \%$ hydroquinone. Eur J Dermatol 5: 680-684

31. Tsilika K, Levy JL, Kang HY, Duteil L, Khemis A, et al (2011). Efficacy of a novel non-hydroquinone in the treatment of melasma: a reflectance confocal microscope study. Lasers Surg Med 43: 985

32. Paine C, Sharlow E, Liebel F, Eisinger M, Shapiro S, et al. (2001) An alternative approach to depigmentation by soybean extracts via inhibition of the PAR-2 pathway. J Invest Dermatol 116: 587-595.

33. Ha JH, Kang WH, Lee JO, Cho YK, Park SK, et al. (2011) Clinical evaluation of the depigmenting effect of Glechoma Hederacea extract by topical treatment for 8 weeks on UV-induced pigmentation in Asian skin. Eur J Dermatol 21 218-222.

34. Altaei T (2012) The treatment of melasma by silymarin cream. BMC Dermato 12: 18.

35. Handog EB, Galang DA, de Leon-Godinez MA, Chan GP (2009) A randomized double-blind, placebo-controlled trial of oral procyanidin with vitamins $A, C, E$ for melasma among Filipino women. Int J Dermatol 48: 896-901.

36. Ni Z, Mu Y, Gulati O (2002) Treatment of melasma with Pycnogenol. Phytother Res 16: $567-571$

37. Martin LK, Caperton C, Woolery-Lloyd H, Avashia N (2012) A randomized double blind placebo controlled study evaluating the effectiveness and tolerability of oral Polypodium leucotomos in patients with melasma. Poster \# 4630. Paper presented at the American Academy of Dermatology, San Diego.

38. 38. Feng XJ, Fu JY, Liu F (2010). Clinical observation on the combined use of acupuncture and herbal medicine for treatment of chloasma. J Tradit Chin Med 29: $163-166$ 
39. Fisk WA, Agbai O, Lev-Tov HA, Sivamani RK (2014) The use of botanically derived agents for hyperpigmentation: a systematic review. J Am Acad Dermatol 70: 352-365.

40. Ahmed AM, Lopez I, Perese F, Vasquez R, Hynan LS, et al. (2013) A randomized, double-blinded, placebo-controlled trial of oral Polypodium leucotomos extract as an adjunct to sunscreen in the treatment of melasma. JAMA Dermatol 149: 981-983.

41. C'de Baca J, Lapham SC, Paine S, Skipper BJ (2000) Victim impact panels: who is sentenced to attend? Does attendance affect recidivism of first-time DWI offenders? Alcohol Clin Exp Res 24: 1420-1426.

42. Wang TJ, An J, Chen XH, Deng QD, Yang L (2014) Assessment of Cuscuta chinensis seeds $x^{3}$ effect on melanogenesis: comparison of water and ethanol fractions in vitro and in vivo. J Ethnopharmacol 154: 240-248.

43. Panda S (1999) A comparative study ofsuperficial facial peeling with trichloroacetic acid and glycolic acid in the cases of resistant melasma. Unpublished MD dissertation, Ranchi University, Ranchi.

44. Francisco-Diaz J, Cristi-Cataluna I, Cruz DD, Verallo-Rowell VM (2004). A double-blind randomized placebo controlled trial on the efficacy and safety of botanical extract (Gigawhite $5 \%$ solution) in the treatment of melasma. J Phil Dermatolo Soc 13: 18-23

45. Khemis A, Kaiafa A, Queille-Roussel C, Duteil L, Ortonne JP (2007) Evaluation of efficacy and safety of rucinol serum in patients with melasma: a randomized controlled trial. Br J Dermatol 156: 997-1004.

46. Thirion L, Piérard-Franchimont C, Piérard GE (2006) Whitening effect of a dermocosmetic formulation: a randomized double-blind controlled study on melasma. Int J Cosmet Sci 28: 263-267.

47. Hantash BM, Jimenez F (2009) A split-face, double-blind, randomized and placebo-controlled pilot evaluation of a novel oligopeptide for the treatment of recalcitrant melasma. J Drugs Dermatol 8: 732-735.
48. Hamann CR, Boonchai W, Wen L, Sakanashi EN, Chu CY, et al. (2014) Spectrometric analysis of mercury content in 549 skin-lightening products: is mercury toxicity a hidden global health hazard? J Am Acad Dermatol 70: 281 287.

49. Chung JY, Choi M, Lee JH, Cho S, Lee JH (2014) Pulse in pulse intense pulsed light for melasma treatment: a pilot study. Dermatol Surg 40: 162-168.

50. Eimpunth S, Wanitphakdeedecha R, Triwongwaranat D, Varothai S, Manuskiatti W (2014) Therapeutic outcome of melasma treatment by dual-wavelength (511 and $578 \mathrm{~nm}$ ) laser in patients with skin phototypes III-V. Clin Exp Dermatol 39 292-297.

51. Wanitphakdeedecha R, Keoprasom N, Eimpunth S, Manuskiatti W (2014) The efficacy in melasma treatment using a $1410 \mathrm{~nm}$ fractional photothermolysis laser. J Eur Acad Dermatol Venereol 28: 293-297.

52. Fabi SG, Friedmann DP Niwa Massaki AB, Goldman MP (2014). A randomized, split-face clinical trial of low-fluence $Q$-switched neodymium-doped yttrium aluminium garnet $(1,064-\mathrm{nm})$ laser versus low-fluence $\mathrm{Q}$-switched alexandrite laser $(755-\mathrm{nm})$ for the treatment of facial melasma. Lasers Surg Med.

53. Jalaly NY, Valizadeh N, Barikbin B, Yousefi M (2014) Low-power fractiona COâ,, laser versus low-fluence Q-switch 1,064 nm Nd:YAG laser for treatment of melasma: a randomized, controlled, split-face study. Am J Clin Dermatol 15: 357-363.

54. Clarys P, Alewaeters K, Lambrecht R, Barel AO (2000) Skin color measurements: comparison between three instruments: the Chromameter $(R)$, the DermaSpectrometer(R) and the Mexameter(R). Skin Res Technol 6: 230238.

55. Uhlenhuth EH, Matuzas W, Warner TD, Paine S, Lydiard RB, et al. (2000) Do antidepressants selectively suppress spontaneous (unexpected) panic attacks? A replication. J Clin Psychopharmacol 20: 622-627. 